\title{
Comparing the Thixotropic and Lightly Solidified Hardening Behavior of a Dredged Marine Clay
}

\author{
Chee-Ming Chan \\ Faculty of Engineering Technology \\ Universiti Tun Hussein Onn Malaysia \\ Batu Pahat, Malaysia \\ chan@uthm.edu.my
}

\author{
Hui-Yen Yong \\ Faculty of Civil \& Environmental Engineering \\ Universiti Tun Hussein Onn Malaysia \\ Batu Pahat, Malaysia \\ hui_yen_90@hotmail.com
}

\begin{abstract}
When a soil is disturbed upon remolding, it may lose part or all of its strength. As time passes, the structural arrangement of the soil particles would be restored to a stable form and the soil would regain hardness under constant volume and water content. The process is known as "thixotropic hardening". On another note, dredged marine soils of the finegrained type can be reused as a backfill material instead of being disposed to the open sea. The rest period required for the relocated soil to regain strength and stiffness, i.e. thixotropic hardening, needs to be estimated precisely. For this purpose, a study on the phenomena of strength and stiffness gain by a dredged marine clay was carried out. The strength and stiffness improvement with time was measured using the vane shear and fall cone tests respectively. The clay was remolded at different water contents in multiples of the soil's liquid limit (LL), namely 0.75LL, 1.00LL and 1.25LL, in order to evaluate the effect of initial water content on thixotropic hardening. A separate series of samples were prepared with light solidification using cement, to examine the possibilities of enhancing the soil's improvement in a shorter rest period. The results showed the dredged marine clay can potentially be used as a backfill material for reclamation works, with lower initial water content and light solidification contributing to accelerated better performance.
\end{abstract}

Keywords- thixotropic hardening; light solidification; dredged marine clay; undrained shear strength; cone penetration

\section{INTRODUCTION}

Dredging activities in shipping channels generate huge amount of dredged marine sediments (DMS). Usually, dredging activities are carried out for the maintenance of navigation channels or the deepening of existing port facilities to cope with large ships [1]. The most widely practiced DMS management solution is to dispose the material to open sea, especially for DMS with are of fine-grained nature (i.e. clay and silt), which have poor engineering properties and limited usage. However, the disposal of DMS in the water could contaminate it and endanger the marine ecosystem, leading to potentially long term, irreversible environmental problems. Hence it is crucial to review and develop a beneficial reuse for DMS, in place of indiscriminate disposal.

Similarly to the mechanism of secondary compression (post- consolidation hardening process), DMS regains strength and hardness under constant volume and water content by thixotropic hardening. This is attributed to the rearrangement of the soil particles to a more stable state. DMS can be potentially reused as a backfill material for reclamation work, assuming that thixotropic hardening contributes to the eventual strength and stiffness gain. As reported in [2], there is some marked improvement in the material when left to rest for certain periods. In addition, the present study also explores the possibilities of shortening the rest period for the strength and stiffness gain of the DMS by employing light solidification with small dosages of cement. Note that the role of cement in the study was mainly to accelerate the thixotropic hardening process and not for solidification purposes. Work pertaining to the solidification of soft soil deposits can be found in the literature, where some of the more recent ones include [3-5].

As it is time-dependent, thixotropic hardening is also known as a kinetic process involving the time effect on the soil's structural destruction / formation mechanisms [6]. Continuous viscosity decrease with time when flow is applied to a previously at-rest sample and it would meet a subsequent recovery when the flow is discontinued [7]. It has also been reported that the effect of thixotropy increases when the soil is within the range of the liquid and plastic limits [2]. Beyond the liquid limit, thixotropic behavior was found to diminish as the water content rises. This is in line with observations made in [8], although it has also been reported that thixotropic effect can be low or negligible at or close to the soil's plastic limit [9]. This suggests the initial water content has a significant effect on the thixotropy phenomenon. The soil could undergo full or partial recovery of strength and stiffness, depending on the material's inherent properties and characteristics. Besides, the process is reversible upon remolding and resting, and vice versa [10].

An understanding of the soil's behavior in regaining timedependent strength and stiffness is necessary to introduce DMS as a potential backfill material, particularly in terms of the rest period. Areas of applications include eroded shoreline rehabilitation, reclamation, construction of road embankments, creation of elevated grounds and other civil engineering projects [11]. For instance, as illustrated in Figure 1, DMS reclamation along shorelines to cope with rising sea levels. As additional time means extra costs in construction businesses, 
practitioners would need to be convinced of the payoff from using a 'greener' material without losing out on the time factor. This paper describes an investigation on the matter with a dredged marine clay retrieved from the Malaysian waters. An additional set of tests were also conducted on the sample lightly solidified with small dosages of cement (i.e. $<10 \%$ ), to ascertain the possibilities of shortened rest period.

\section{MATERIALS AND METHODS}

\section{A. Remoulding of dredged marine clay}

The DMS sample was obtained from a dredged site in the waters of Melaka, a historical city of Malaysia. Key properties of the sample are summarized in Table I. Note that the natural water content of the sample was higher than its liquid limit. However, in order to examine the thixotropic effect at different water contents, the soil was remolded at three water contents in multiples of the liquid limit (LL), i.e. 0.75LL, 1.00LL and 1.25LL. The soil was semi-dried in a pan over a portable stove, where the heating process was carefully controlled and monitored with regular measurement of the water content.

The remolded soil was next poured into a plastic mold of $9.5 \mathrm{~cm} \times 30 \mathrm{~cm} \times 11 \mathrm{~cm}$ dimension (Figure 2). The mixture was placed in 4 layers. For each layer, the mold was lightly tapped on the bench to remove any entrapped air from the partially liquefied material. The soil bed was kept at $60 \mathrm{~mm}$ thick, with each layer's thickness measuring approximately $15 \mathrm{~mm}$. The layer thickness was used as guide in maintaining the volume of the soil bed in each sample prepared. A separate set of soil bed was prepared similarly at $1.25 \mathrm{LL}$ water content, but with the addition of $2-8 \%$ of cement (as per dry mass of soil). The small cement dosages added were, as mentioned earlier, to gain insights to the possibilities of hastening the strength and stiffness gain within a shorter rest period. The percentage range of chemical contents in the cement is given in Table II. Measurements with the laboratory vane shear and cone penetrometer were then carried out on the samples over a 7-day period, at intervals of $0,0.5,1,2,4,8,24,48,96$ and 168 hours.

TABLE I. PHYSICO-CHEMICAL PROPERTIES OF DREDGED SAMPLE

\begin{tabular}{|c|c|c|c|}
\hline Material Properties & Value & $\begin{array}{c}\text { Oxide } \\
\text { element }\end{array}$ & $\begin{array}{c}\text { Content } \\
(\%)\end{array}$ \\
\hline \multicolumn{2}{|c|}{ Particle size distribution, \% } & $\mathrm{CaO}_{2}$ & 0.10 \\
\hline Sand & $9 \%$ & $\mathrm{SiO}_{2}$ & 57.10 \\
\hline Silt & $18 \%$ & $\mathrm{Al}_{2} \mathrm{O}_{3}$ & 21.50 \\
\hline Clay & $69 \%$ & $\mathrm{Fe}_{2} \mathrm{O}_{3}$ & 7.63 \\
\hline \multicolumn{2}{|c|}{ Atterberg limit, \% } & $\mathrm{K}_{2} \mathrm{O}$ & 3.04 \\
\hline Liquid limit & $54.20 \%$ & $\mathrm{Cl}$ & 2.27 \\
\hline Plastic limit & $30.72 \%$ & $\mathrm{MgO}$ & 2.17 \\
\hline Plasticity Index & $23.48 \%$ & $\mathrm{CaO}$ & 1.98 \\
\hline \multirow{2}{*}{$\begin{array}{c}\text { Natural moisture } \\
\text { content }(\%)\end{array}$} & \multirow{2}{*}{$103.44 \%$} & $\mathrm{SO}_{3}$ & 1.36 \\
\hline & & $\mathrm{Na}_{2} \mathrm{O}$ & 1.34 \\
\hline Classification of soil & $\mathrm{CH}$ & $\mathrm{TiO}_{2}$ & 1.05 \\
\hline Specific gravity, $\mathrm{G}_{\mathrm{s}}$ & 2.53 & & \\
\hline
\end{tabular}

TABLE II. LIMITS OF CHEMICAL CONTENTS IN CEMENT

\begin{tabular}{|c|c|}
\hline Chemical compound & Content (\%) \\
\hline $\mathrm{CaO}$ & $60-67$ \\
\hline $\mathrm{SiO}_{2}$ & $17-25$ \\
\hline $\mathrm{Al}_{2} \mathrm{O} 3$ & $3-8$ \\
\hline $\mathrm{Fe}_{2} \mathrm{O}_{3}$ & $0.5-0.6$ \\
\hline $\mathrm{MgO}_{2}$ & $0.1-0.4$ \\
\hline $\mathrm{Na}_{2} \mathrm{O}, \mathrm{K}_{2} \mathrm{O}$ & $0.2-1.3$ \\
\hline $\mathrm{SO}_{3}$ & $1-3$ \\
\hline
\end{tabular}

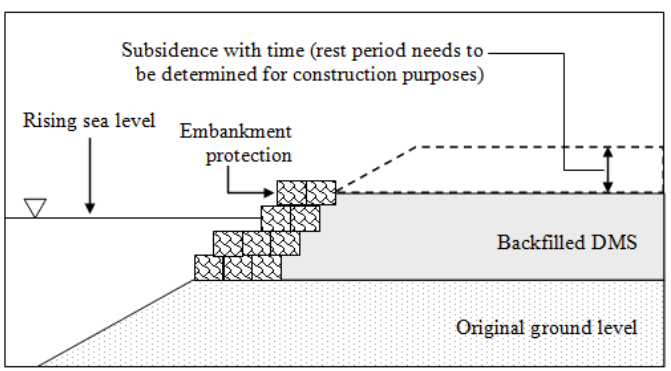

Fig. 1. Using DMS as a backfill material in countering rising sea level

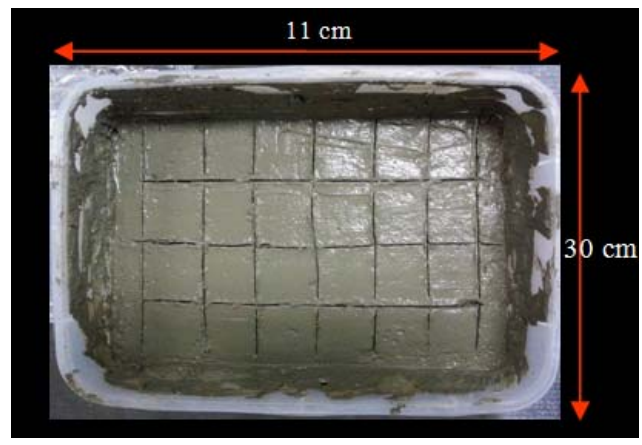

Fig. 2. Remolded soil bed with grids marked out for the measurements

\section{B. Laboratory vane shear test}

The increase in shear strength by thixotropic hardening was determined by laboratory vane shear test (Figure 3a), according to BS1377 [12]. Laboratory vane shear test was considered most appropriate since the soil sample was classified as cohesive soil of fine-grained type with very low strength. A standard $12.7 \mathrm{~mm}$ wide and $12.7 \mathrm{~mm}$ long vane was used in the test. The most appropriate torsion spring was chosen based on the maximum stress each torsion spring can sustain. Torque was applied to the vane by rotation at $10^{\circ}$ per minute. The minimum centre-to-centre distance for each test point was kept at about $35 \mathrm{~mm}$ to minimize disturbance from the adjacent, previous test point. The undrained shear strength (cu) can then be calculated by (1):

$$
c_{u}=\frac{2 T}{p D^{2}\left(H+\frac{D}{3}\right)}
$$

where $\mathrm{T}$ is the measured torque at peak, $\mathrm{D}$ is the vane diameter, and $\mathrm{H}$ is the vane height. 


\section{Fall cone test}

The fall cone test (Figure 3b) was conducted to measure the shear resistance developed from the improved stiffness of the soil with time. The test was performed according to BS1377 [12], with omissions of the plotting and calculations, as normally carried out if the test was intended for measuring liquid limit. The cone ( $80 \mathrm{~g}$ with an apex angle of $30^{\circ}$ ) was first placed just above the soil's surface, then dropped under its own weight for 5 seconds before the reading was taken. The cone penetration depth would decrease with time as soil's stiffness increased, i.e. resistance against the cone penetration would be gained over time. As such, it follows that the cone penetration depth can be related with the undrained shear strength of the soil, as strength and stiffness are known to rise in tandem [13].

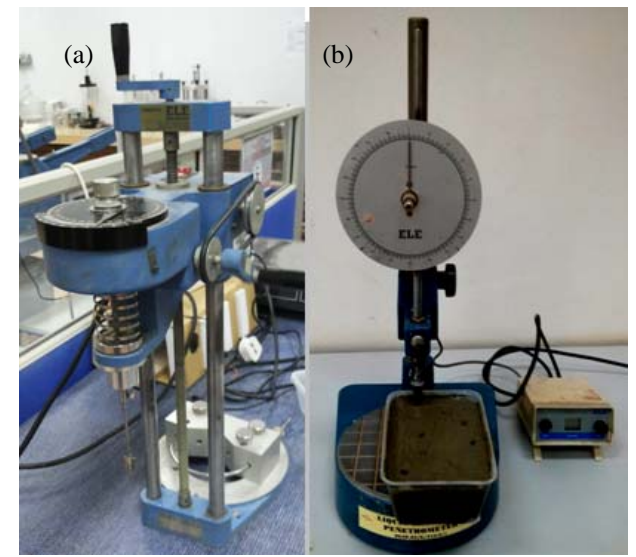

Fig. 3. (a) Vane shear and (b) fall cone tests

\section{RESULTS AND DISCUSSIONS}

\section{A. Undrained shear strength of DMS}

Figure 4 shows the undrained shear strength for the DMS samples at different water contents. It is apparent that samples 1.00LL and 1.25LL underwent negligible strength improvement over the 1-week period. Compared to sample 0.75LL, the initial strength recorded was about 1.5-4 times that of the other two samples. The subsequent rise in strength was charted markedly over 48 hours, before the strength gain reached a relative plateau. This indicates that for this particular DMS, an initial water content lower than the liquid limit is necessary to enable thixotropic hardening to take place. At water contents beyond the liquid limit, the soil would be too liquefied and susceptible to flocculation, resulting in repulsion of the soil particles in the water-logged matrix instead of settling down to a more rigid structure.

The cone penetration depth vs time elapsed plots are shown in Figure 5. All samples underwent a similar rate of penetration in the first 8 hours, though in comparison, the readings for sample 1.25LL seemed to record less dramatic change with time (i.e. more gentle gradient of the initial rise of the plot). Sample 1.25LL also reached a plateau later than the other two samples. However note that the initial penetration was far higher for sample $1.25 \mathrm{LL}$, which was approximately twice that of the other samples. Besides, both samples 1.00LL and 0.75LL demonstrated slight reduction in the penetration depth after 8 hours of time lapse. Sample 1.25LL took a longer time to gain resistance against the cone penetration, i.e. plateau was attained at about 36 hours.

\section{B. Cone penetration depth}

In general the cone penetration rate corresponded with the strength gain rate, but the major departure of sample $0.75 \mathrm{LL}$ in terms of strength (Figure 4) was not observed in the fall cone test. Indeed, samples 1.00LL and 1.25LL were remarkably close in terms of the cone penetration rate (Figure 5). This suggests limitation of the sensitivity of the fall cone test, as well as possible bleeding in the high water content soils resulting in weakened upper layer of the soil bed.

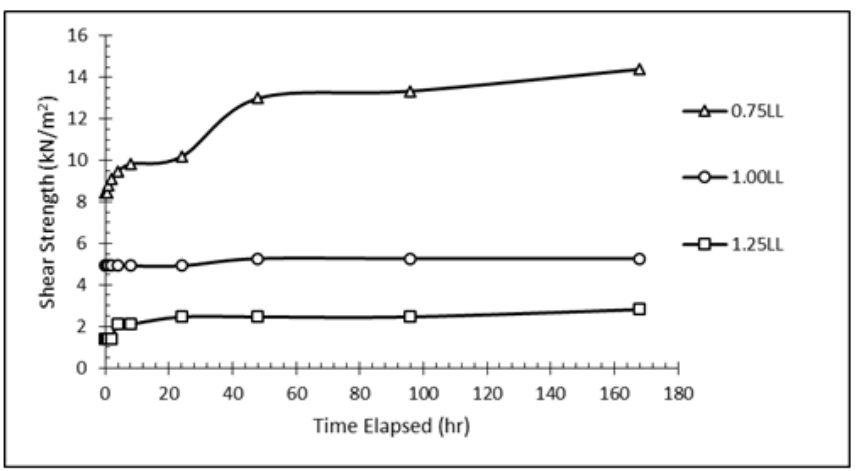

Fig. 4. Variation in shear strength developed from thixotropic hardening

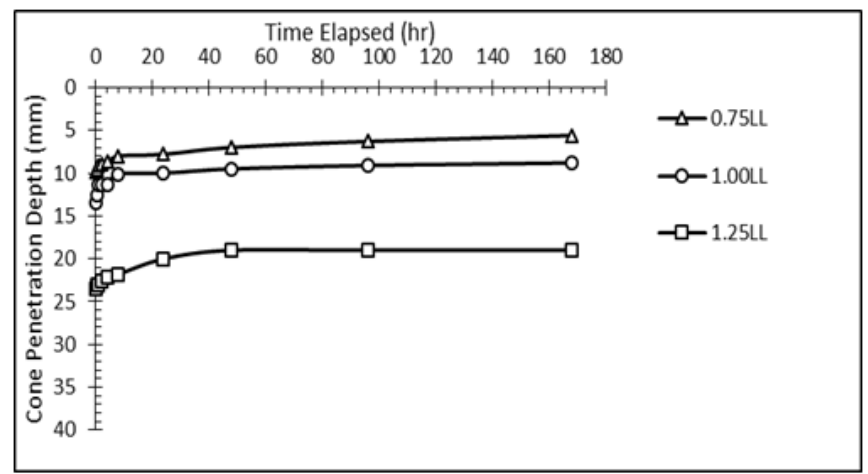

Fig. 5. Variation in cone penetration depth developed from thixotropic hardening

\section{Comparison between natural and lightly solidified DMS}

Figure 6 shows the combined undrained shear strength plots of the natural DMS and lightly solidified samples. It can be seen that the strength of the lightly solidified samples with 6$8 \%$ cement increased dramatically. On the other hand, cement addition of less than $5 \%$ did not seem to contribute much to the strength improvement, even after the prolonged rest period of a week. Clearly the efficacy of light solidification was overwhelmed by the excessive water content present in the soil, 
as is evidential in the low lying plots even below that of sample 0.75LL. The cement dosage was inadequate to induce solidification of the wet soil. This suggests a threshold cement dosage for meaningful strength gain. Besides, the rising trends of samples 1.25LL (6\% cement) and (8\% cement) underline the benefits of continuous strength gain of the DMS, despite the high initial water content.

Taking into account the time factor, and comparing the plots of samples with $6-8 \%$ cement addition, the strength gain rate was dependent on the amount of cement added. This is highlighted by the significant early strength gain recorded by sample 1.25LL (8\% cement) within the first 24 hours, before the transition to a more gentle rise in strength. The sample with $6 \%$ cement addition had a less remarkable strength gain rate in the first 48 hours, after which a sharp rise was observed till approximately 100 hours. The strength gain rate then declined and returned to approximately the same rate as in the initial stage. Gradient indicators (triangles with dashed lines) are included in Figure 6 next to the 6\% cement plot to illustrate the different strength gain rates. Such variations in the rate of improvement was not observed in the sample with $8 \%$ cement addition.

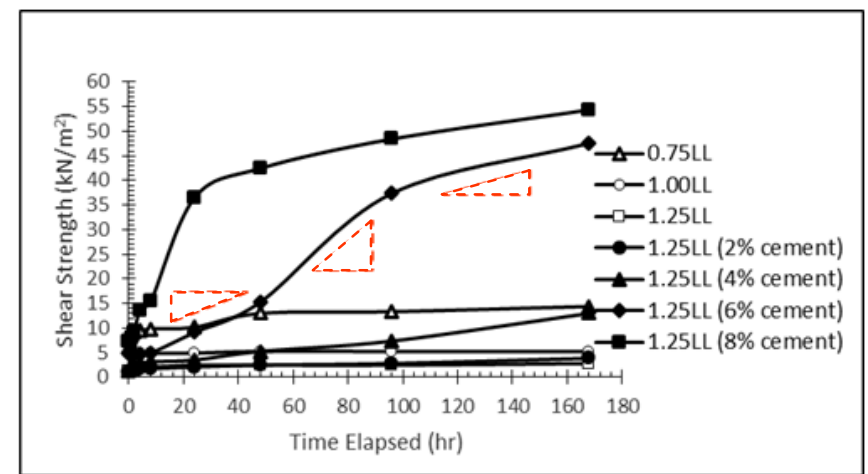

Fig. 6. Comparison of variation in undrained shear strength of untreated DMS with cement treated DMS with time

The combined cone penetration depth plots are shown in Figure 7 . The resistance against cone penetration was best achieved by the samples with $6-8 \%$ cement addition, which is in line with the strength gain plots in Figure 6. The hardening effect for samples with 1-4\% cement addition which was otherwise not captured in the strength plots was obvious (Figure 7). Note the $2 \%$ cement and $4 \%$ cement plots lying very close to 1.25LL and 1.00LL respectively, after 48 hours. This could be explained by the limited solidification efficacy of $2 \%$ cement addition to the soil. The $4 \%$ cement sample, however, was effectively solidified to attain the same stiffness gained by the soil at lower initial water content, i.e. 1.00LL. These results point to the contribution of cement addition in shortening the improvement rate of the DMS.

The delayed hardening effect of the $6 \%$ cement sample was not observed in Figure 7, where both 6\% and 8\% cement samples showed similar improvement rate. Nonetheless the eventual stabilization of the cone penetration resistance rate was similar to those seen in the strength plots. The continuous hardening effect was absent in the cone penetration plots too, with all samples recording plateaus after 48 hours. This is perhaps an indicator of the limitations of the fall cone test in assessing the strength and stiffness gain in DMS, with or without light solidification.

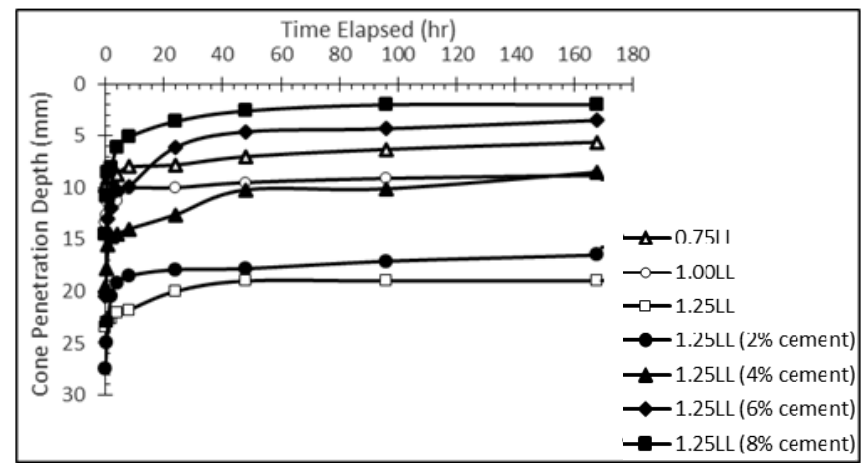

Fig. 7. Comparison of variation in cone penetration depth of untreated DMS with cement treated DMS with time

\section{CONCLUSIONS}

The main conclusions are as follows:

1. The strength and cone penetration resistance improvement rate of the samples follow the ascending order of $0.75 \mathrm{LL}>1.00 \mathrm{LL}>1.25 \mathrm{LL}$, indicating the setbacks of high initial water contents on the rest period.

2. The fall cone method seemed less sensitive to the rather small improved structure of the soil with time, which could be attributed to a weakened upper layer of the soil bed due to bleeding.

3. Light solidification was effective with a minimum cement dosage of $6 \%$. The strength as well as the strength gain rate both improved markedly, and showed signs of prolonged improvement beyond 7 days.

4. The fall cone test was able to capture the distinction between the solidification efficacy with $2-4 \%$ cement, but was insensitive to the continuous hardening effect post 48 hours.

5. Overall, small cement dosages (i.e. $>6 \%$ in this case) were sufficient to shorten the rest period of the DMS. In fact, it was found to contribute to prolonged improvement of the soil too.

\section{REFERENCES}

[1] W. S. W. Salim, W. S., N. A. M. Noor, S. F. Sadikon, M. F. Arshad, N. Wahid, S. M. Salleh, "The preliminary investigation on the dredged marine sediment of Kuala Perlis as a potential brick material”, 5th International Conference on Environmental and Computer Science (ICECS2012), pp. 25-29, Thailand, 2012

[2] S. Seng, H. Tanaka, "Properties of very soft clays: A study of thixotropic hardening and behavior under low consolidation pressure", Soils and Foundations, Vol. 52, No. 2, pp. 335-345, 2012

[3] S. Horpibulsuk, W. Phojan, A. Suddeepong, A. Chinkulkijniwat, M. D. Liu, "Strength development in blended cement admixed saline clay", Applied Clay Science, Vol. 55, pp. 44-52, 2012 
[4] N. C. Consoli, L. Festugato, C. G. da Rocha, R. C. Cruz, "Key parameters for strength control of rammed sand-cement mixtures: Influence of types of portland cement”, Construction and Building Materials, Vol. 49, pp. 591-597, 2013

[5] C. M. Chan, "Influence of mix uniformity on the induced solidification of dredged marine clay”, Environmental Earth Sciences, Vol. 71, No. 3, pp. 1061-1071, 2014

[6] A. Y. Malkin, "Non-Newtonian viscosity in steady-state shear flows", Journal of Non-Newtonian Fluid Mechanics, Vol. 192, pp. 48-65, 2013

[7] J. Mewis, N. J. Wagner, "Thixotropy”, Advances in Colloid and Interface Science, Vol. 147-148, pp. 214-227, 2009

[8] A. W. Skempton, R. D. Northey, "Sensitivity of clays", Geotechnique, Vol. 3, No. 1, pp. 40-51, 1952

[9] H. B. Seed, C. K. Chan, "Thixotropic characteristics of compacted clays”, ASCE Journal of Soil Mechanics and Foundation Engineering, Vol. 83(SM4), pp. 1427-1435, 1957
[10] M. D. Braja, Fundamentals of Geotechnical Engineering. CENGAGE Learning, UK, 2013

[11] C. M. Chan, A. Shamsuddin, "Sustainable geo-materials from agricultural and geo-wastes: Reborn and viva!”, Australian Journal of Basic and Applied Research, Vol. 7, No. 11, pp. 87-103, 2013

[12] British Standard Institution, British Standard BS 1377-1: Methods of test for soils for civil engineering purposes. London, UK, 1990

[13] H. Tanaka, H. Hirabayashi, M. Tatsuya, K. Hiroaki, "Use of fall cone test as measurement of shear strength for soft clay materials", Soils and Foundations, Vol. 52, No. 4, pp. 590-599, 2012 